\title{
Chapter 35 \\ Monitoring Soil Salinisation as a Strategy \\ for Preventing Land Degradation: A Case Study in Sicily, Italy
}

\author{
Giuseppina Crescimanno, Kenneth B. Marcum, Francesco Morga, \\ and Carlo Reina
}

\begin{abstract}
Water demand is increasing worldwide. In regions affected by water scarcity such as those located in the Mediterranean basin, water supplies are already degraded, or subjected to degradation processes, which worsen the water shortage. In Sicily, the increasing scarcity of good quality water is expanding irrigation with saline-sodic waters, thus enhancing the risk of secondary salinization and sodification. Adequate management practices are urgently needed for sustainable use of saline/sodic waters. This chapter illustrates how the Geonics EM-38 probe was used for monitoring salinization in a Sicilian area where irrigation with saline water is increasingly practiced, and the risk of salinisation and desertification is envisaged. Electrical conductivity of bulk soil (ECa) measurement grids were taken with the EM-38 in a Sicilian vineyard at several dates, both prior to, and following irrigations, with two distinct irrigation treatments of different salinities $(0.6$ and $1.6 \mathrm{dS} \mathrm{m}^{-1}$ respectively). Though both water sources contributed to field salinity, high salinity source had a more adverse effect. This investigation proved the usefulness of EM-38 for efficient, rapid monitoring of the progressive effects of different irrigation strategies on soil salinization.
\end{abstract}

Keywords Salinity control $\cdot$ Sodic water irrigation $\cdot$ Crop yield $\cdot$ Sicily

\subsection{Introduction}

Arid and semi-arid regions of the world are variably affected by soil salinization and sodification. Saline and sodic soils cover about $10 \%$ of the total arable lands and exist in over 100 countries. Of irrigated lands, about 344 millions of hectare (23\%) are salty and another 560 millions of hectare (37\%) are sodic. Saline and sodic soils, although affecting mostly arid and semi-arid regions, are not limited

\footnotetext{
G. Crescimanno $(\otimes)$

Dipartimento ITAF, Università di Palermo, 90128 Palermo, Italy

e-mail: gcrescim@unipa.it
} 
to these regions. According to estimates, 10 millions of hectares of irrigated land are abandoned yearly as a consequence of the adverse effect of irrigation, mainly secondary salinization and sodification (Szabolcs, 1994). Furthermore, demand for fresh water is progressively increasing, due to rapid population growth and urbanization worldwide, resulting in problems associated with aquifer depletion, i.e. salt-water intrusion and use of salt-compromised waters for irrigation (Marcum, 2006). Salinization of water and soil represents a pre-condition for desertification, defined as "degradation of land in arid, semi-arid and dry sub-humid areas resulting mainly from adverse human impact" (UNEP, 1991).

Salinity may have negative direct effects on crop yield by (a) reducing the ability of plant roots to absorb water, due to increased soil osmotic potential, or (b) the direct effects of saline ions, resulting in either toxicity or nutrient imbalances. Threshold relationships between the soil electrical conductivity (EC) and crop yield have been empirically determined for several crops and can be used to evaluate the influence of saline irrigation water on agricultural production. Sodicity adversely impacts soil structure, particularly finer textured soils, due to deflocculation of clay aggregates. Direct effects include reduced soil hydraulic conductivity (Crescimanno et al., 1995), and therefore reduced leaching potential, resulting in accelerated soil salinization. Indirect effects include reduced soil macropores and oxygen exchange, resulting in anaerobic rhizosphere conditions. Root oxygen starvation typically results in reduction, or loss of plant salinity tolerance, due to reduced activity of ATP-driven ion partitioning/exclusion mechanisms at the root endodermis (Barrett-Lennard, 2003).

Salinity in irrigation water is defined as the total sum of dissolved inorganic ions and molecules. Soil salinity is generally measured by determining the electrical conductivity of the soil solution. EC measured in the saturated extract $\left(\mathrm{EC}_{\mathrm{sat}}\right)$, a technique initially developed by USSL, is the most commonly used method of estimating soil salinity that uses reference water content (Rhoades et al., 1989). Though the method is labour-intensive and time consuming, it remains the standard benchmark for estimating soil salinity. Methods suitable for rapid assessment of soil salinity are necessary for survey and monitoring of large land areas susceptible to salinity degradation.

Application of electromagnetic induction sensor technology (EM) makes possible, after calibration, rapid surveys for determination of areas having the greatest hazard of salinisation. In these areas, detailed investigation is necessary to develop countermeasures and strategies suitable to control desertification. EM provides a measurement of the EC of the "bulk soil", or ECa (Hendrickx et al., 1992). As ECa is influenced not only by the chemical and physical properties of the soil solution, but also by those of the solid phase (soil texture, mineralogical composition of the soil), calibration is necessary for the individual soil monitored by EM, by taking an ECe grid sample of the field, thus allowing the conversion of ECa data into $\mathrm{EC}_{\text {sat }}$ (Corwin and Lesch, 2003; Lesch et al., 2005).

The use of saline-sodic waters for irrigation is prevalent in Sicily. Consider that in the last 30 years, no more than 300 million $\mathrm{m}^{3}$ of good quality water have been available for irrigation, versus a requirement for 1,600 million $\mathrm{m}^{3}$. As a result, 
increasing attention is being paid to the long-term hazards associated with prolonged application of these waters on Sicilian soils (Crescimanno, 2001b). A number of international and national projects have been developed since 1998 in Sicily with the objective of developing integrated approaches for sustainable management of irrigation (Crescimanno, 2001a; Crescimanno and Garofalo, 2005, 2006, 2007). This investigation is part of the "Evolution of cropping systems as affected by climate change" (CLIMESCO) project (2007-2009). CLIMESCO has the objective of developing management scenarios for optimizing the use of limited water resources while concurrently minimizing salinisation and the risk of desertification (Crescimanno and Marcum, 2009). This chapter illustrates results of a methodology based on EM-38 measurements for monitoring the soil salinisation risk in two different irrigation treatments in a vineyard located in western Sicily (Mazara del Vallo, Trapani) during the 2007 irrigation season.

\subsection{Materials and Methods}

\subsubsection{Field and Irrigation Description}

Apparent soil electrical conductivity (ECa) was measured in a vineyard (Fig. 35.1) in southwest Sicily, in a soil with silty clay textural class (44\% clay, $46 \%$ silt, $10 \%$ sand). Soils like this are common in Sicily and have high shrink/swell potential, being particularly susceptible thus to salinization. Irrigation water derived from two sources (lake and well), having salinities of 1.6 and $0.6 \mathrm{ECw}$, respectively. The initial irrigation was made on 12 July 2007 with lake water throughout the field to establish uniform conditions. Second irrigation was a 2-day event, with lake water applied on the left (L) side of the field on 17 July, followed by well water on the right (R) side on 18 July. Third irrigation was again a 2-day event, with lake water applied on the L side of the field on 25 July, followed by well water on the R side on 26 July. Table 35.1 reports the irrigation schedule adopted. Irrigation amount was $15 \mathrm{~mm}$ depth per event. Reference evapotranspiration deficit (ETd) was on average 5-7 mm day $^{-1}$ throughout the irrigation period, where ETd $=$ ETo - measured precipitation (there was no measurable rainfall during the experimental period).

\subsubsection{EM-38 Measurements}

EM-38 measurements were taken using a grid pattern across the $\mathrm{L}$ and $\mathrm{R}$ treatments plots before the first irrigation, and subsequently after irrigation events. Figure 35.2 illustrates the plants rows located in the L and R treatments, and the sites along the rows where EM-38 measurements were taken. The first measurement was taken on 21 June, prior to irrigation. Two subsequent measurements were taken on 18 July, and again on 23 July, following the first two irrigation events (12 July and 17-18 July). The final measurement was taken on 27 July, following the third irrigation event. Table 35.1 reports the EM-38 measurement schedule adopted. 


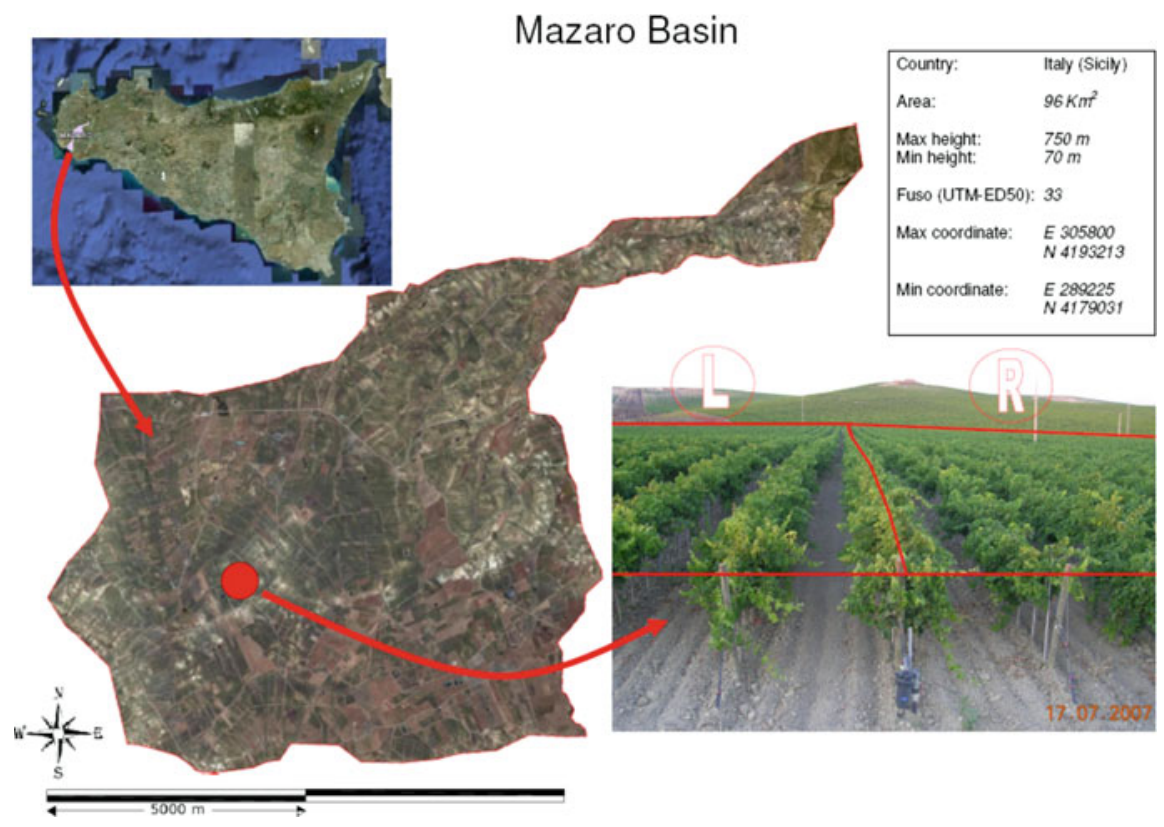

Fig. 35.1 Mazaro basin, Sicily (Italy), and location of the two treatments (Left, L, and Right, R) at the Foraci Farm

Table 35.1 Irrigation schedule adopted, measurement date, zonal mean $\mathrm{EC}_{\mathrm{sat}}$ and the relative crop yield calculated according to Maas and Hoffman (1977)

\begin{tabular}{|c|c|c|c|c|c|}
\hline \multirow[b]{2}{*}{ Irrigation date } & \multirow{2}{*}{$\begin{array}{l}\text { EM-38 } \\
\text { measurement } \\
\text { date }\end{array}$} & \multicolumn{2}{|c|}{$\begin{array}{l}\text { ZM_EC } \text { sat } \\
\left(\mathrm{dS} \mathrm{m}^{-1}\right)\end{array}$} & \multicolumn{2}{|c|}{$\begin{array}{l}\text { Relative crop yield (\%) } \\
\text { (Maas and Hoffman, } \\
\text { 1977) }\end{array}$} \\
\hline & & $\mathrm{R}$ & $\mathrm{L}$ & $\mathrm{R}$ & $\mathrm{L}$ \\
\hline 20 June 2007 & - & - & - & - & - \\
\hline - & 21 June 2007 & 1.70 & 1.77 & 98.1 & 97.4 \\
\hline 12 July 2007 & - & - & - & - & - \\
\hline- & 18 July 2007 & 1.56 & 1.83 & 99.5 & 96.8 \\
\hline 17-18 July 2007 & - & - & - & - & - \\
\hline- & 23 July 2007 & 1.51 & 1.59 & 100 & 99.1 \\
\hline 26 July 2007 & - & - & - & - & - \\
\hline - & 27 July 2007 & 1.58 & 1.76 & 99.3 & 97.5 \\
\hline
\end{tabular}

\subsubsection{Instrumentation and Technique}

ECa was monitored using a grid pattern, by an electromagnetic inductive meter (Geonics EM-38 probe, Geonics Limited, Mississauga, Ontario). The Geonics EM-38 sensor has an intercoil spacing of $1 \mathrm{~m}$ and operates at a frequency of $13.2 \mathrm{kHz}$, allowing measurement of ECa to effective depths of approximately 1 

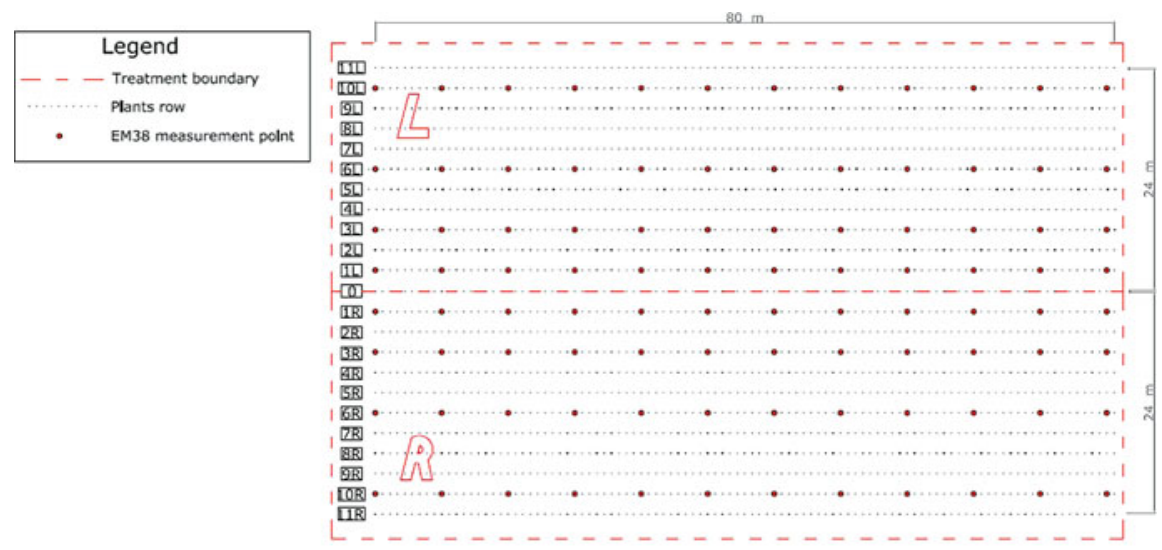

Fig. 35.2 Left (L) and Right (R) treatments at the Foraci farm, plants rows and EM-38 measurement points

and $2 \mathrm{~m}$ when placed at the ground level in horizontal and vertical configuration respectively. An EM transmitter coil located in one end of the instrument induces circular eddy-current loops in the soil. The magnitude of these loops is directly proportional to the electrical conductivity (EC) of the soil in the vicinity of that loop. Each current loop generates a secondary electromagnetic field that is proportional to the value of the current flowing within the loop. The receiver coil intercepts a fraction of the secondary induced electromagnetic field from each loop, and the sum of these signals is amplified and formed into an output voltage that is linearly related to a depth-weighted soil EC.

For calibration of ECa data, soil samples were taken for measurements of the soil electrical conductivity, $\mathrm{EC}_{\text {sat }}$ (saturated extract) at representative points within the grid pattern, at $60 \mathrm{~cm}$ depth.

\subsection{Results and Conclusions}

Vertical EM-38 readings (EMv) were converted into $\mathrm{EC}_{\mathrm{sat}}$ values according to the following calibration equation, obtained via data distributions taken in April 2007 and subsequently in June 2007:

$$
\mathrm{EC}_{\mathrm{sat}}=0.36 \cdot \mathrm{EMv}+1.10
$$

with $R$ (correlation coefficient) $=0.83(R$ significant at $P=0.001)$ and SEE (standard error of estimate) $=0.16 \mathrm{dS} \mathrm{m}^{-1}$.

$\mathrm{EC}_{\text {sat }}$ values were elaborated with geostatistical techniques (Wackernagel, 2003) in order to create maps showing salinity distribution following irrigation events in both $\mathrm{L}$ and $\mathrm{R}$ treatments. $\mathrm{EC}_{\mathrm{sat}}$ values were interpolated in a GIS environment, using a Gaussian semivariogram to express spatial correlation. Zonal statistics calculated 

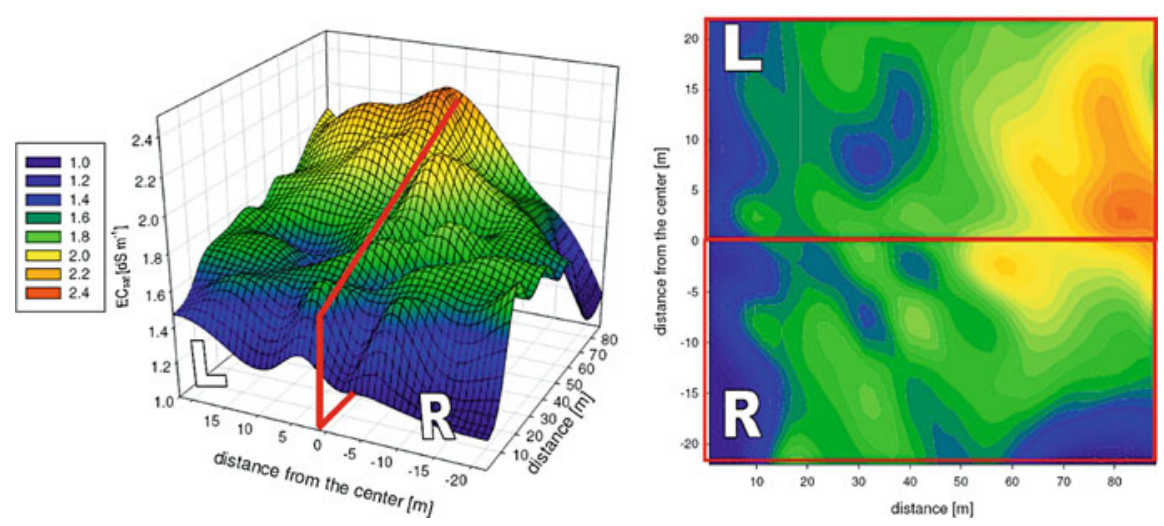

Fig. 35.3 Salinity distribution (3-D) and salinity map (2-D) on 21 June 2007

by $\operatorname{ArcGIS}{ }^{\circledR}$ were used to determine zonal mean $\mathrm{EC}_{\text {sat }}\left(\mathrm{ZM} \_\mathrm{EC}_{\text {sat }}\right)$ for the $\mathrm{L}$ and $\mathrm{R}$ treatments, the value of which is reported in Table 35.1 and illustrated in Fig. 35.7.

First EM-38 survey (21 June) revealed the initial salinity distribution in the field prior to any irrigation (Fig. 35.3). The 3-D and 2-D maps show an increasing salinity gradient across the entire field, with $\mathrm{EC}_{\mathrm{sat}}$ values ranging from approximately $1 \mathrm{dS} \mathrm{m}^{-1}$ up to $2.4 \mathrm{dS} \mathrm{m}^{-1}$. Higher salinity values occurred in the left part of the field, with ZM_EC sat $_{\text {e }}$ equal to $1.77 \mathrm{dS} \mathrm{m}^{-1}$ in $\mathrm{L}$, and $1.69 \mathrm{dS} \mathrm{m}^{-1}$ in $\mathrm{R}$ side, respectively.

Second EM-38 survey (18 July) describes the salinity distribution subsequent to irrigation of the whole field with lake water on 12 July, followed by irrigation of the left side only with lake water on 17 July. The 3-D and 2-D maps, illustrated in Fig. 35.4, reveal an increase in salinity on the L side, with $\mathrm{ZM}_{-} \mathrm{EC}_{\text {sat }}=1.82$ $\mathrm{dS} \mathrm{m} \mathrm{m}^{-1}$ (Fig. 35.7 and Table 35.1). However, salinity had a considerable spatial variability, and in some parts of the field salinity increased from 2 to $2.4 \mathrm{dS} \mathrm{m}^{-1}$. The maps also show a decrease in salinity in the $\mathrm{R}$ side, with $\mathrm{ZM} \_\mathrm{EC}_{\mathrm{sat}}=1.56 \mathrm{dS} \mathrm{m}^{-1}$.

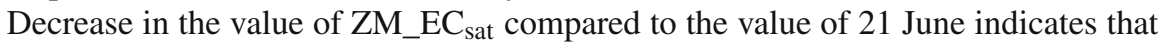
some salt-leaching took place on the R side only, decreasing ZM_EC sat from 1.69 to $1.56 \mathrm{dS} \mathrm{m}^{-1}$.

Third EM-38 reading (23 July) describes the salinity distribution following the initial irrigation of the $\mathrm{R}$ side with well water on 18 July, subsequent to irrigation of the $\mathrm{L}$ side with lake water on 17 July. Though this irrigation was expected to result in a further decrease in salinity on the R side only (Fig. 35.5), there was actually a decrease in salinity on both $\mathrm{R}$ and $\mathrm{L}$ sides, compared to the previous reading of 18 July (Fig. 35.4). This would indicate that this irrigation event resulted efficient in salt leaching on both $\mathrm{R}\left(\mathrm{ZM} \_\mathrm{EC}_{\text {sat }}\right.$ decreased from 1.56 to 1.51$)$ and $\mathrm{L}$ sides

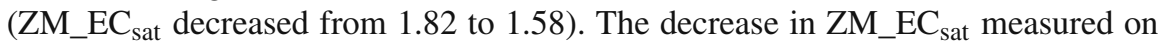
the $\mathrm{L}$ side could also be due to a significant salt redistribution from the $\mathrm{L}$ to the $\mathrm{R}$ side of the field resulting from slope effects, as this salinity reading was taken some days after irrigation events occurred. 

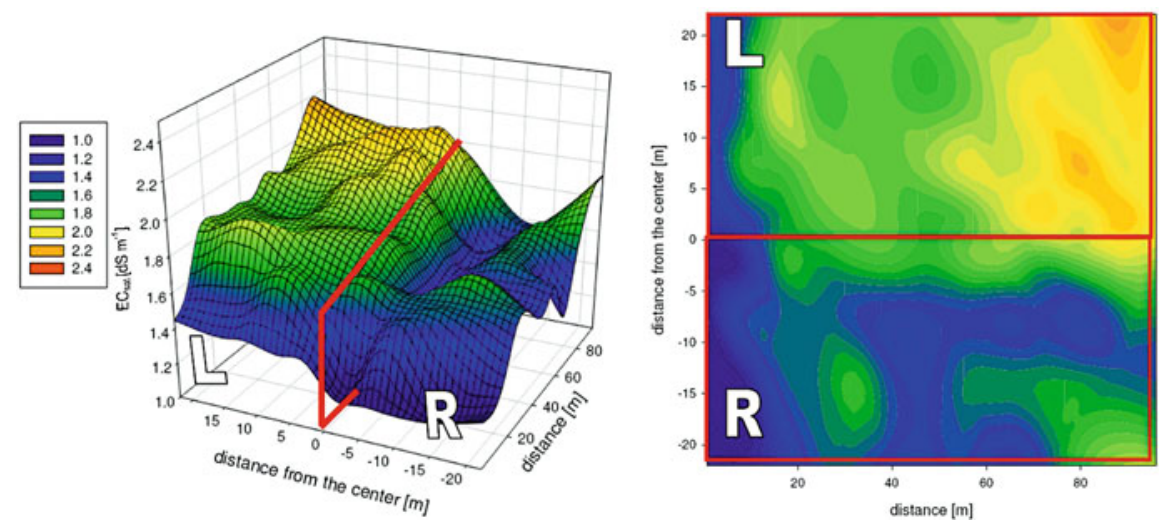

Fig. 35.4 Salinity distribution (3-D) and salinity map (2-D) on 18 July 2007
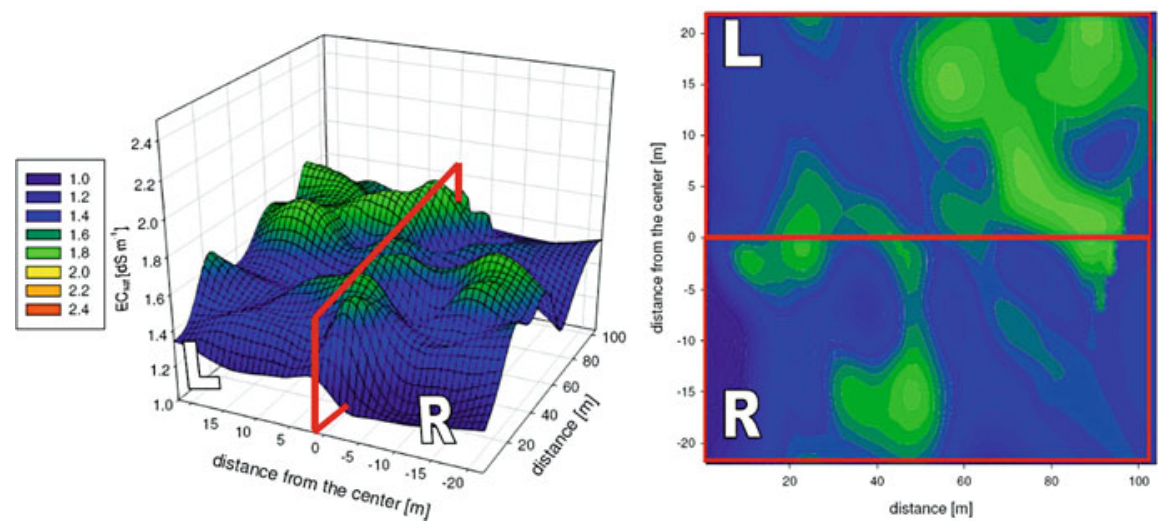

Fig. 35.5 Salinity distribution (3-D) and salinity map (2-D) on 23 July 2007

The final EM-38 reading (27 July) describes salinity distribution following irrigation of the whole field with lake (25 July, L side) and well (26 July, R side) water (Fig. 35.6). Left side shows an increase in salinity, in both maximum values $\left(\mathrm{EC}_{\mathrm{sat}}\right.$ up to $\left.2.4 \mathrm{dS} \mathrm{m}^{-1}\right)$, and $\mathrm{ZM} \_\mathrm{EC}_{\text {sat }}\left(\mathrm{ZM} \_\mathrm{EC}_{\mathrm{sat}}=1.75 \mathrm{dS} \mathrm{m}^{-1}\right.$, Table 35.1$)$, and also in the relative field area affected, compared to the previous date, indicating a clear impact due to irrigation with the saline water source. Salinity is not uniformly distributed, with some areas undergoing maximum accumulation of salts. However, the $\mathrm{R}$ side also shows an increase in the $\mathrm{ZM} \mathrm{EC}_{\text {sat }}\left(\mathrm{ZM}_{-} \mathrm{EC}_{\mathrm{sat}}=1.58 \mathrm{dS} \mathrm{m}^{-1}\right)$ compared to survey of 23 July (ZM_EC sat $_{1.51} \mathrm{dS} \mathrm{m}^{-1}$ ), which could also be explained by redistribution of salts from the $\mathrm{L}$ to the $\mathrm{R}$ side, as previously observed in the 23 July survey.

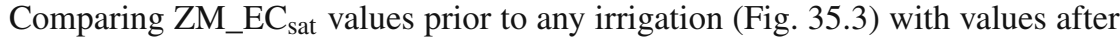
all irrigations (Fig. 35.6) in the $\mathrm{R}$ and $\mathrm{L}$ sides, it can be seen that there was significant salt leaching in the $\mathrm{R}$ side, with a reduction of $6.5 \%$ in salinity from 21 June to 

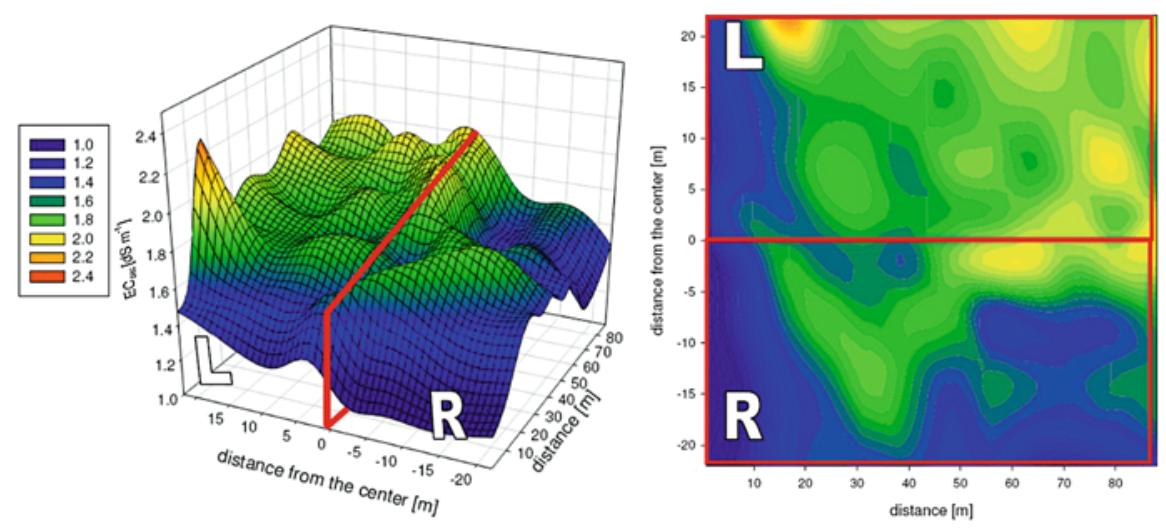

Fig. 35.6 Salinity distribution (3-D) and salinity map (2D) on 27 July 2007

Fig. 35.7 Zonal mean electrical conductivity (ZM_EC $\mathrm{sat}_{\text {at }}$ ) values for the $\mathrm{R}$ and $\mathrm{L}$ treatments.

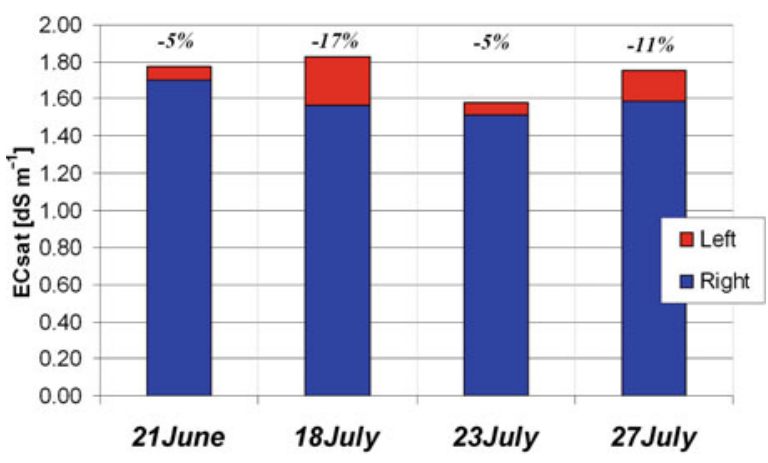

27 July 2007 (Fig. 35.7). This leaching might have been more significant if no flux from $\mathrm{L}$ to $\mathrm{R}$ had taken place during the irrigation season. In addition, an insignificant reduction in salinity (equal to $1.12 \%$ ) was caused by irrigation in the $\mathrm{L}$ side from 21 June to 27 July 2007, perhaps also due to lateral water flux.

In conclusion, use of a moderate salinity water source (well water treatment) for irrigation proved to be an efficient practice, decreasing salinity in the R side of the field compared to salinity conditions observed in the L plot, following an annual

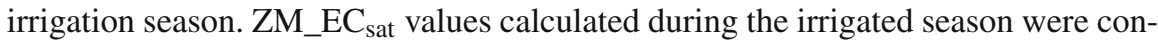
verted into crop yield reduction according to the Maas and Hoffman equation (1977) (Table 35.1). Relative crop yield values calculated after irrigation events confirm more favourable salinity and crop conditions occurring in the R plot, relative to the $\mathrm{L}$ plot. Results indicate replacing lake water with well water irrigation to be a more sustainable practice for preventing soil salinisation in western Sicily.

This investigation also proved the usefulness of EM-38 for efficient, rapid monitoring of the progressive effects of different irrigation waters on soil salinisation, and for analysing spatial distribution of salinity before and after irrigation. Further 
investigation is under way using the same methodology in order to predict longterm salinity distribution changes, and to develop management scenarios aimed at reducing salinization and soil degradation.

Acknowledgments This research was supported by Ministero dell'Università e della Ricerca scientifica (MIUR, Italy) under the project: "Evoluzione dei sistemi colturali in seguito ai cambiamenti climatici" (CLIMESCO).

\section{References}

Barrett-Lennard, E.G. (2003). The interaction between waterlogging and salinity in higher plants: Causes, consequences, and implications. Plant Soil 253:35-54.

Corwin, D.L. and Lesch, S.M. (2003). Application of soil electrical conductivity to precision agriculture: Theory, principles, and guidelines. Agronomy Journal 95:455-471.

Crescimanno, G., Iovino, M. and Provenzano, G. (1995). Influence of salinity and sodicity on soil structural and hydraulic characteristics. Soil Science Society of America Journal 59: 1701-1708.

Crescimanno, G. (2001a). An integrated approach for sustainable management of irrigated lands susceptible to degradation/desertification. Final Report ENV7-CT97-0681.

Crescimanno, G. (2001b). Irrigation practices affecting land degradation in Sicily. PhD Dissertation Thesis. Wageningen University, The Netherlands, ISBN 90-5808-426-4.

Crescimanno, G. and Garofalo, P. (2005). Application and evaluation of the SWAP model for simulating water and solute transport in a cracking clay soil. Soil Science Society of America Journal 69:1943-1954.

Crescimanno, G. and Garofalo, P. (2006). Management of irrigation with saline water in cracking clay soils. Soil Science Society of America Journal 70:1774-1787.

Crescimanno, G. and Garofalo, P. (2007). Irrigation strategies for optimal use of saline water in Mediterranean agriculture. International Conference on "Water Saving in Mediterranean Agriculture and Future Research needs". CIHEM, Bari, 14-17 February 2007.

Crescimanno, G. and K.B. Marcum (2009). Irrigation, salinization and desertification. Evolution of Cropping Systems as Affected by Climate Change. (CLIMESCO), Aracne (in press) (ISBN 978-88-548).

Hendrickx, J.M.H., Baerends, B., Raza, Z.I., Sadig, M. and Akram Chardhry, M. (1992). Soil salinity assessment by electromagnetic induction of irrigated land. Soil Science Society of America Journal 56:1933-1941.

Lesch, S.M., Corwin, D.L. and Robinson, D.A. (2005). Apparent soil electrical conductivity mapping as an agricultural management tool in arid zone soils. Computers and Electronics in Agriculture 46:351-378.

Maas, E.V. and Hoffman, G.J. (1977). Crop salt tolerance - current assessment. Journal of Irrigation and Drainage Division, ASCE 103:115-134.

Marcum, K.B (2006). Use of saline and non-potable water in the turfgrass industry: Constraints and developments. Agricultural Water Management 80:132-146.

Rhoades, J.D., Nahid, A., Manteghi, P., Shouse J. and Alves, W.J. (1989). Estimating soil salinity from saturated soil-paste electrical conductivity. Soil Science Society of America Journal 53:428-433.

Szabolcs, I. (1994). Prospects of soil salinity for the 21st century. 15th International Congress of Soil Science. Acapulco, Mexico.

UNEP. (1991). Status of desertification and implementation of the United Nations plan of action to combat desertification. UNEP, Nairobi.

Wackernagel, H. (2003). Multivariate Geostatistics: An Introduction with Application. Springer, New York, p. 387. 